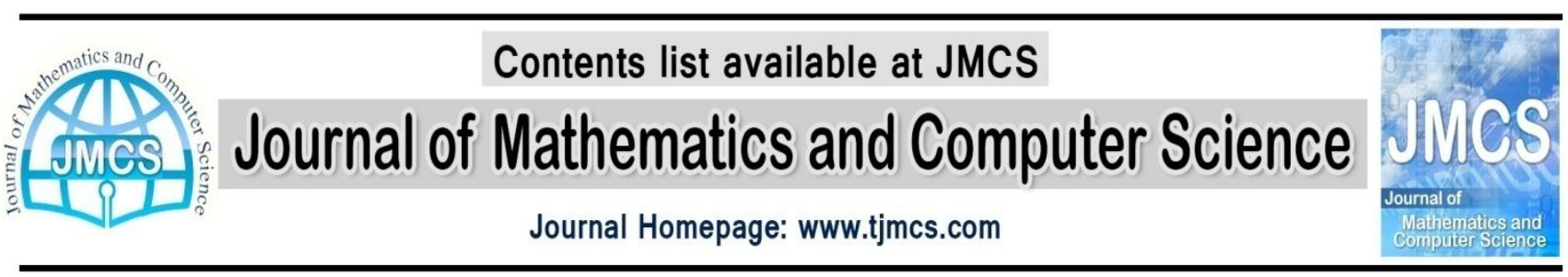

\title{
Prediction of Saturated Vapor Pressures Using Non-Linear Equations and Artificial Neural Network Approach
}

\author{
Mehrdad Honarmand, Ehsan Sanjari*, Hamidreza Badihi \\ Department of Mechanics, Tiran Branches, Islamic Azad University, Isfahan, Iran \\ *sanjary@gmail.com
}

Article history:

Received February 2013

Accepted May 2013

Available online July 2013

\begin{abstract}
A new method to estimate vapor pressures for pure compounds using an artificial neural network (ANN) is presented. A reliable database including more than 12000 data point of vapor pressure for testing, training and validation of ANN is used. The designed neural network can predict the vapor pressure using temperature, critical temperature, and acentric factor as input, and reduced pressure as output with $0.211 \%$ average absolute relative deviation. 8450 data points for training, 1810 data points for validation, and 1810 data points for testing have been used to the network design and then results compared to data source from NIST Chemistry Web Book. The study shows that the proposed method represents an excellent alternative for the estimation of pure substance vapor pressures and can be used with confidence for any substances.
\end{abstract}

Keywords: Vapor pressure, ANN, neural network, correlation, non-linear

\section{Introduction}

Thermodynamic properties of pure fluids such as vapor pressure are very important in design of different industries for instant petrochemical, pharmaceutical and chemical processes. The thermophysical properties can be obtained from equation of state [1]. Two parameters equations of state such as Redlich-Kwong [2], Soave-Redlich-Kwong [3] and Peng-Robinson [4] were widely used in predicting Pressure-Volume-Temperature (PVT) phase behavior of compounds.

Vapor-pressure equations try to provide the temperature dependence of the saturated pressure of a fluid along the (liquid + vapor) coexistence curve. Since the Clapeyron equation was proposed in 1834, there has been a plethora of vapor-pressure equations described for both correlating and predicting experimental data of pure fluids [5]. 
Due to the absence and the limited range of vapor pressure experimental data in the literature, some researchers have used different correlations to estimate enthalpies and saturated vapor pressure [513].

Numerous empirical vapor-pressure equations have been published, the best known are those of Wagner [14], Antoine [15], Clausius, Frost-Kalkwarf, Cox, Gomez-Thodos, Lee-Kesler, Wagner, Ambrose-Walton, Riedel [16, 17], Lemmon-Goodwin [18], Voutsas et al. [13], and Mejbri et al., [8]. The most common of all is Antoine type equation [15], which has three-parameters, but is valid only within a limited temperature range.

Among all available methods for calculating vapor pressure of pure fluids, one of the most efficient and accurate method is artificial neural network (ANN). Neural networks are information-processing patterns based on the biological nervous systems, such as the brain, process information [19]. ANN has recently been used to predict pressure volume temperature (PVT) properties of pure substances by Moghadasi et al. [20]. Rohani and coworkers [21], considered artificial neural network system and SAFT equation in obtaining vapor pressure and liquid density of pure alcohols. By using ANN, Lazzus [22] predicted solid vapor pressures for organic and inorganic compounds, and Gandhidasan et al. [23] estimated vapor pressures of aqueous desiccants for cooling applications.

The main focus of this study is designing an appropriate ANN to predict saturated vapor pressure of pure substances with higher accuracy than all other models in desired temperature and using more than 12000 source data points (NIST Chemistry WebBook [24]). Finally the results of the ANN model are compared to the mostly used methods.

\section{Vapor pressure prediction models}

\subsection{Antoine vapor pressure correlation}

The Antoine vapor pressure correlation was modified based on the Clapeyron equation. It has been widely used to estimate the vapor pressure over limited temperature ranges [15]. The proposed correlation is shown below:

$$
\ln P_{v p}=A-\frac{B}{T+C}
$$

Where, $P v p$ is the vapor pressure $(\mathrm{mmHg}), T$ is the temperature $\left({ }^{\circ} \mathrm{C}\right)$ and the constant values of $A, B$ and $C$ for considered refrigerants are presented in Appendix $A$ in (Reid et al., 1987).

\subsection{Lee-Kesler's method}

The Lee-Kesler's method [25] is one of the successful methods to predict the vapor pressure using the three-parameter formulations.

$$
\begin{aligned}
& \ln P_{v p r}=f^{(0)}\left(T_{r}\right)+\omega f^{(1)}\left(T_{r}\right) \\
& f^{(0)}=5.92714-\frac{6.09648}{T_{r}}-1.28862 \ln T_{r}+0.169347 T_{r}^{6}
\end{aligned}
$$




$$
f^{(1)}=15.2518-\frac{15.6875}{T_{r}}-13.4721 \ln T_{r}+0.43577 T_{r}^{6}
$$

Where $P_{v p r}$ is the reduced vapor pressure which equals to $P / P_{c}$, and $P_{c}$ is the critical pressure (pascal), $\omega$ is the acentric factor $T_{r}$ is the reduced temperature which equals to $T / T_{c}$, where $T_{c}$ is the critical temperature $(\mathrm{K})$ of the fluid. Values for $T_{c}$ and $P_{c}$ can be found in the literature for many pure substances $[17,26-28]$.

\subsection{Ambrose-Walton Corresponding States Method}

Ambrose and Walton [17] developed another representation of the Pitzer expansion with an additional term $f^{(2)}\left(T_{r}\right)$.

$$
\begin{aligned}
& \ln P_{v p r}=f^{(0)}\left(T_{r}\right)+\omega f^{(1)}\left(T_{r}\right)+\omega^{2} f^{(2)}\left(T_{r}\right) \\
& f^{(0)}=\frac{-5.97616 \tau+1.29874 \tau^{1.5}-0.60394 \tau^{2.5}-1.06841 \tau^{5}}{T_{r}} \\
& f^{(1)}=\frac{-5.03365 \tau+1.11505 \tau^{1.5}-5.41217 \tau^{2.5}-7.46628 \tau^{5}}{T_{r}} \\
& f^{(2)}=\frac{-0.64771 \tau+2.41539 \tau^{1.5}-4.26979 \tau^{2.5}+3.25259 \tau^{5}}{T_{r}} \\
& \omega=-\frac{\ln \left(P_{c} / 1.01325\right)+f^{(0)}\left(T_{b r}\right)}{f^{(1)}\left(T_{b r}\right)}
\end{aligned}
$$

Where $\omega$ is the acentric factor, $P_{c}$ is the critical pressure (bars) of the fluid, and $\tau=1-T_{\mathrm{r}}$.

\subsection{Riedel Corresponding States Method}

Riedel [29] proposed a vapor pressure equation of the form:

$\ln P_{v p r}=A+\frac{B}{T_{r}}+C \ln T_{r}+D T_{r}^{6}$

The $T_{r}^{6}$ term allows description of the inflection point of the vapor pressure curve in the highpressure region. Parameters $A, B, C$, and $D$ are function of $T, T_{c}$. $T_{b}$, and $P_{c}$.

\subsection{Wagner equation}


Wagner [14] used an elaborate statistical method to develop an equation for representing the vapor pressure behavior of nitrogen and argon over the entire temperature range for which experimental data were available. The resulting equation is:

$\ln \left(\frac{P_{s a t}}{P_{c}}\right)=\frac{A \tau+B \tau^{1.5}+C \tau^{2.5}+D \tau^{5}}{1-\tau}$

Where $\tau=1-\frac{T}{T_{c}}$

Where $P_{c}$ is the critical pressure, $T_{c}$ is the critical temperature, and $A, B, C$, and $D$ are constant substance-dependent parameters. Forero and coworkers [30], determined Wagner equation parameters for 257 substances with low deviations.

\subsection{Velasco equation}

Velasco et al. [5] developed a new simple equation for predicting the temperature dependence of the vapor-pressure of a pure substance along the entire (liquid + vapor) coexistence curve, from the triple point to the critical point. The formulation of this method is presented as follow:

$\ln P_{r}=\frac{T_{t}}{T} \ln P_{t r} \frac{1-t}{\left(1+a_{1} t\right)\left[1+b_{0} t\left(t-t_{b}\right)\right]}$

With

$t=\frac{T_{r}-T_{t r}}{1-T_{t r}}$

$t_{b}=\frac{T_{b r}-T_{t r}}{1-T_{t r}}$

Where $a_{1}$ and $b_{0}$ are constant substance-dependent parameters, $T_{t}$ is triple point temperature, and $T_{b}$ is normal boiling point temperature.

\section{Artificial Neural Network (ANN)}

Artificial neural network system is a simple method for modeling, which does not need explicit formulation of exact mathematical or physical relations between input and output data. It carries out the modeling based on simple mathematical functions. So it can be used in case of either complex relation between input and output data or no available relation at all. Therefore, ANN is being used in recent decades in process modeling, process control, fault diagnosis, error detection, data reconciliation and process analysis [21].

ANNs have been applied successfully in various fields of mathematics, engineering, medicine, economics, meteorology, psychology, neurology and many others. They have also been used in 
weather and market trends forecasting, in the prediction of mineral exploration sites, in electrical and thermal load prediction, in adaptive and robotic control and many others [31].

Neural networks have large degrees of freedom. Hence they are capable of modeling extremely complex functions by capturing the non-linearity of the process studied providing an efficient alternative to the traditional statistical methods [32]. The structure of the information-processing system is constituted of an assemblage of several highly-interconnected elements of processing called neurons, working together to process the information and solve the problem. They are the result of scientific investigations that use mathematical formulations to model nervous system operations. The resulting techniques are being successfully applied in a variety of everyday technical, business, industrial, and medical applications [19].

The typical structure of a three layer feed forward ANN is schematically presented in Figure1.

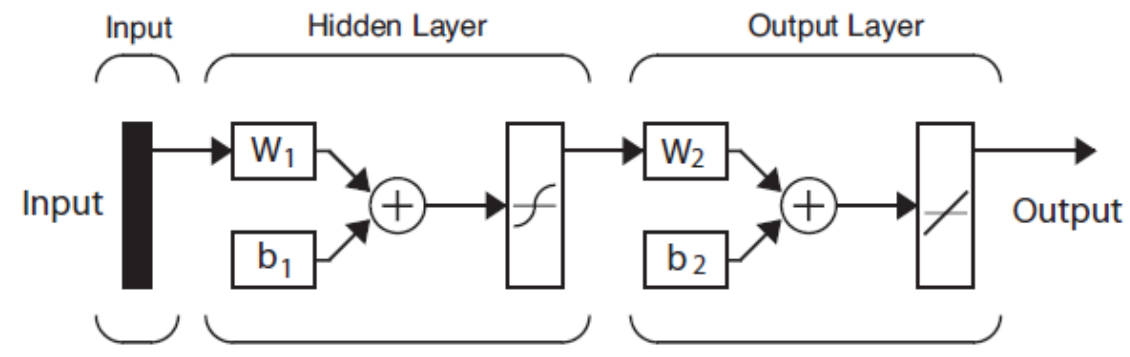

Figure1: The schematics structure of the three-layer feed forward neural network used in this study.

A neural network consists of numbers of simple processing elements called neurons. Each neuron of the neural network is connected to others by means of direct communication links, each with an associated weight, which represents information being used by the network to solve the problem. The output of a neuron is computed from the following equation:

$O_{j}=f\left(\sum_{i=1}^{n} w_{j i} x_{i}+b_{j}\right)$

Where $O_{j}=$ output of $j$ th neuron, $f=$ activation or transfer function, $b_{j}=$ bias of $j$ th neuron, $w_{j i}=$ synaptic weight corresponding to $i$ th synapse of $j$ th neuron, $x_{i}=i$ th input signal to $j$ th neuron, $n=$ number of input signals to $j$ th neuron [33].

During training the weights and biases of the network are iteratively adjusted to minimize the network performance functions. One of typical performance function, used for training feed forward neural networks, is the network average absolute relative deviation percent (AARD \%) that is presented as follow:

$A A R D \%=\frac{1}{N} \sum_{i=1}^{N}\left|\frac{z_{i, \exp }-z_{i, \text { calc }}}{z_{i, \exp }}\right| \times 100$

Through different types of neural networks, the back propagation learning algorithm is the most commonly used algorithm to predict the vapor pressure of pure substances. Several back- 
propagations training methodologies exist, which include the Levenberg-Marguardt Algorithm (LMA), the Scaled Conjugate Gradient (SCG), the Pola-Ribiere Conjugate Gradient (PCG) and others. A review of investigations using similar applications indicates that the LMA is sufficiently robust and produces accurate ANNs [34]. The LMA, that similar to Gauss-Newton method, is used in a backpropagation of error manner to reduce the average absolute relative deviation of the output.

The large collection of patterns needed to make a good quality ANN is commonly divided into three subsets, namely: training, validation, and test sets. The validation set is used to indicate the deviation produced during the training. This set is not used to alter the biases and weights, but serves to illustrate when the training should stop. Typically the deviation that obtained with the set of validation should be reduce during the training step, but should increase as the network starts to learn the specific training patterns used in the training set. The testing set is used to check the quality of the partitioning of the whole pattern set into these subsets. Thus, if the error in the testing set reaches a minimum value at a significantly various iteration number of that in which the minimum occurs with the validation set, this might indicate a poor division of the original data set $[32,35]$.

A set of data containing critical pressure, temperature, critical temperature, acentric factor, and saturated vapor pressure was collected from data bank (NIST Chemistry WebBook [24]). The data bank contains more than 12000 points of saturated vapor pressure.

By using LM algorithm that is more accurate than other back-propagation methods, more than $70 \%$ of data set is used to train each ANN, $15 \%$ used to validation, and $15 \%$ of this set is used to testing designed ANN. The decrease of the mean square error (MSE) during the training, validation, and testing process of this topology is shown in Figure2.

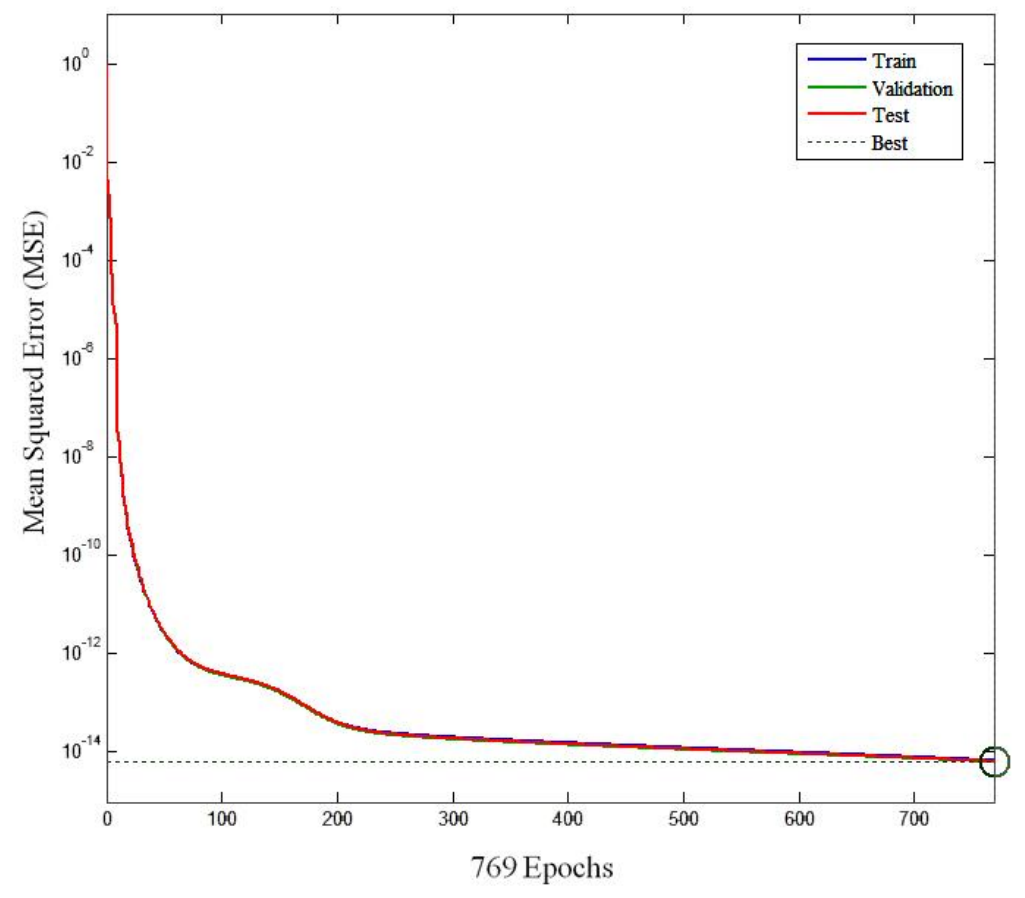

Figure2: Variation of mean square error with training, validation and testing epochs

Number of hidden neurons has been systematically varied to obtain a good estimate of the trained data. To find the optimum number of nodes in the hidden layer, which provides good estimates of 
the output, different number of neurons was considered. The criterion for selection was AARD\% between network output and training data. The results are illustrated in Figure3. As shown in Figures3, architecture of ANN having 15 neurons gave the least average relative error for data set with AARD\% of 0.211 . Figure4 shows the network architecture with 15 neurons in hidden layer.

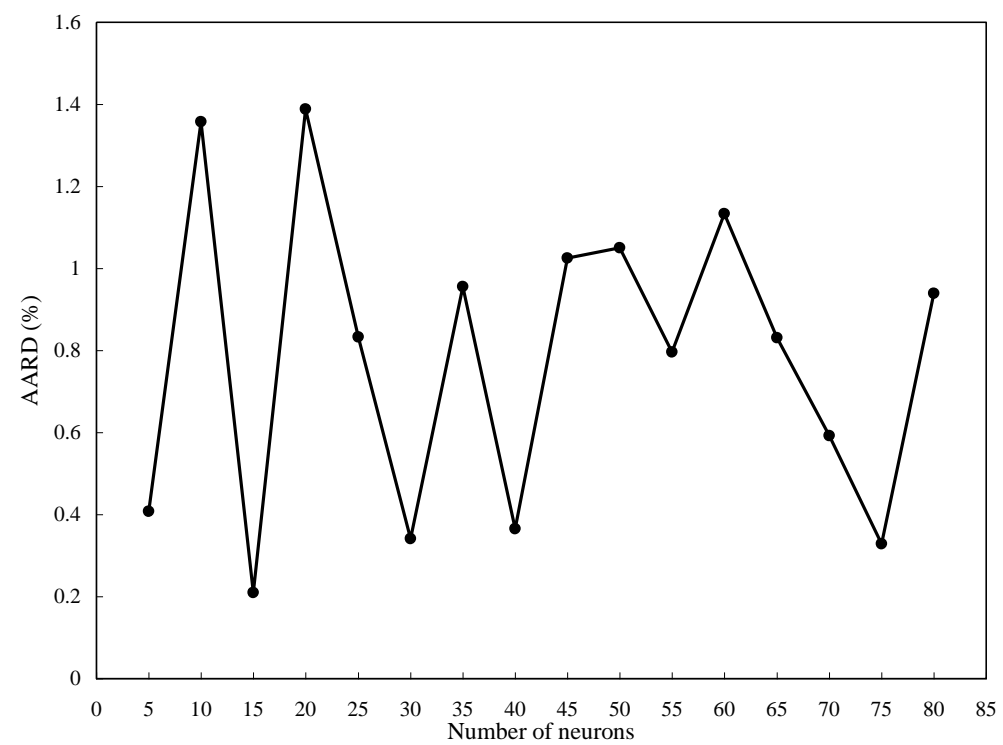

Figure3: Determining the optimum number of neurons

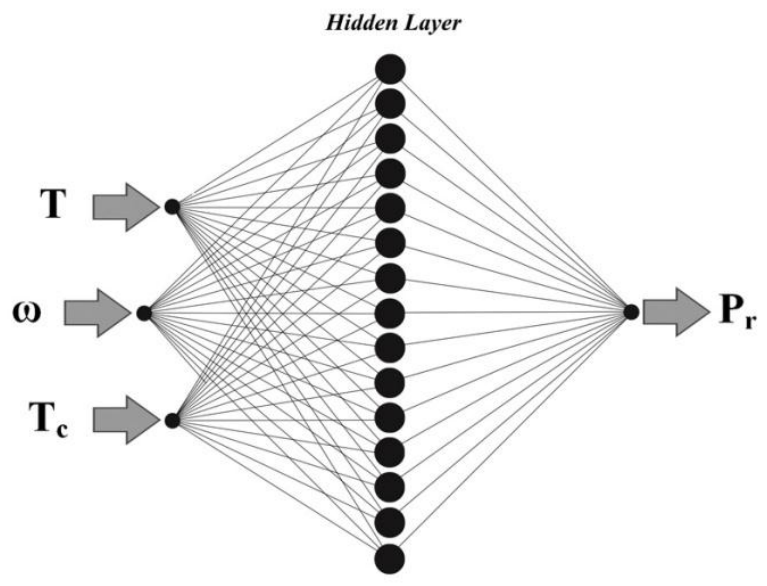

Figure4: Designed neural network structure

\section{Results and discussion}

We carried out calculations for 75 pure substances. The values of the vapor pressure, temperature, critical pressure, critical temperature, boiling point, and acentric factor, were taken from data bank (NIST Chemistry WebBook [24]). The number of data points, pressure and temperature ranges, 
values of critical temperature, critical pressure, and acentric factor for each substance in presented in Table1.

Table1: Main characteristics of the considered substances

\begin{tabular}{|c|c|c|c|c|c|c|c|c|}
\hline Substance & $\begin{array}{l}\text { Data } \\
\text { Points }\end{array}$ & $\begin{array}{c}T_{\min }, \\
\mathrm{K}\end{array}$ & $\begin{array}{c}T_{\max } \\
\mathrm{K}\end{array}$ & $\begin{array}{c}P_{\min } \\
\text { bar }\end{array}$ & $\begin{array}{c}P_{\text {max }} \\
\text { bar }\end{array}$ & $T_{c}, \mathrm{~K}$ & $P_{c}$, bar & $\omega$ \\
\hline $\mathrm{C}_{1}$ & 194 & 94.2 & 190.6 & 0.180 & 45.992 & 190.6 & 45.99 & 0.011 \\
\hline $\mathrm{C}_{2}$ & 139 & 157.0 & 305.3 & 0.171 & 48.718 & 305.3 & 48.72 & 0.099 \\
\hline $\mathrm{C}_{3}$ & 122 & 197.8 & 369.8 & 0.176 & 42.477 & 369.8 & 42.48 & 0.152 \\
\hline $\mathrm{i}-\mathrm{C}_{4}$ & 126 & 224.0 & 407.8 & 0.176 & 36.290 & 407.8 & 36.29 & 0.184 \\
\hline $\mathrm{n}-\mathrm{C}_{4}$ & 133 & 233.6 & 425.1 & 0.172 & 37.960 & 425.1 & 37.96 & 0.201 \\
\hline$n-C_{5}$ & 126 & 265.8 & 469.7 & 0.173 & 33.710 & 469.7 & 33.70 & 0.251 \\
\hline$n-C_{6}$ & 130 & 295.0 & 507.8 & 0.176 & 30.429 & 507.8 & 30.34 & 0.299 \\
\hline $\mathrm{C}_{7}$ & 123 & 322.0 & 540.1 & 0.180 & 27.311 & 540.1 & 27.36 & 0.349 \\
\hline $\mathrm{C}_{8}$ & 128 & 345.2 & 569.3 & 0.172 & 24.978 & 569.3 & 24.97 & 0.393 \\
\hline $\mathrm{C}_{9}$ & 122 & 367.8 & 594.6 & 0.173 & 22.820 & 594.6 & 22.81 & 0.443 \\
\hline $\mathrm{C}_{10}$ & 123 & 389.4 & 617.7 & 0.177 & 21.014 & 617.7 & 21.03 & 0.488 \\
\hline $\mathrm{C}_{12}$ & 118 & 427.3 & 658.1 & 0.176 & 18.176 & 658.1 & 18.17 & 0.574 \\
\hline 2,2-dimethyl propane & 201 & 256.6 & 433.7 & 0.354 & 31.963 & 433.7 & 31.96 & 0.196 \\
\hline 2-methyl pentane & 112 & 287.9 & 497.7 & 0.181 & 30.426 & 497.7 & 30.40 & 0.280 \\
\hline 2-methyl butane & 117 & 258.7 & 460.4 & 0.177 & 33.757 & 460.4 & 33.96 & 0.230 \\
\hline $\mathrm{CO}$ & 199 & 68.8 & 132.9 & 0.173 & 34.982 & 132.9 & 34.93 & 0.050 \\
\hline $\mathrm{CO}_{2}$ & 201 & 216.6 & 304.1 & 5.180 & 73.773 & 304.1 & 73.77 & 0.224 \\
\hline $\cos$ & 154 & 191.8 & 378.8 & 0.182 & 63.688 & 378.8 & 63.70 & 0.098 \\
\hline Methanol & 128 & 298.6 & 512.6 & 0.174 & 81.040 & 512.6 & 81.04 & 0.562 \\
\hline Cyc-Hexane & 182 & 305.5 & 553.6 & 0.180 & 40.750 & 553.6 & 40.75 & 0.209 \\
\hline Cyc-Propane & 201 & 273.0 & 398.3 & 3.427 & 55.689 & 398.3 & 55.80 & 0.131 \\
\hline $\mathrm{D}_{2} \mathrm{O}$ & 171 & 332.0 & 643.9 & 0.172 & 216.60 & 643.9 & 216.71 & 0.364 \\
\hline Dutrium & 196 & 18.7 & 38.3 & 0.195 & 16.476 & 38.3 & 16.65 & -0.175 \\
\hline Ethene & 155 & 145.0 & 282.4 & 0.183 & 50.417 & 282.4 & 50.42 & 0.087 \\
\hline Flourine & 160 & 72.1 & 144.4 & 0.172 & 52.394 & 144.4 & 51.72 & 0.045 \\
\hline $\mathrm{H}_{2}$ & 182 & 15.6 & 33.0 & 0.172 & 12.784 & 33.1 & 12.96 & -0.219 \\
\hline $\mathrm{H}_{2} \mathrm{~S}$ & 201 & 187.7 & 373.1 & 0.233 & 89.987 & 373.1 & 90.01 & 0.100 \\
\hline $\mathrm{He}$ & 160 & 2.8 & 5.2 & 0.171 & 2.264 & 5.2 & 2.27 & -0.382 \\
\hline $\mathrm{Ne}$ & 201 & 24.6 & 44.5 & 0.435 & 26.786 & 44.5 & 26.79 & -0.039 \\
\hline $\mathrm{Ar}$ & 201 & 83.8 & 150.7 & 0.689 & 48.630 & 150.7 & 48.63 & -0.002 \\
\hline \multicolumn{9}{|c|}{350} \\
\hline
\end{tabular}




\begin{tabular}{|c|c|c|c|c|c|c|c|c|}
\hline $\mathrm{Kr}$ & 201 & 115.8 & 209.5 & 0.735 & 55.255 & 209.5 & 55.25 & -0.001 \\
\hline Xe & 201 & 161.4 & 289.7 & 0.817 & 58.420 & 289.7 & 58.42 & 0.004 \\
\hline $\mathrm{N}_{2}$ & 194 & 65.0 & 125.9 & 0.175 & 33.447 & 126.2 & 33.90 & 0.040 \\
\hline $\mathrm{N}_{2} \mathrm{O}$ & 201 & 182.3 & 309.5 & 0.878 & 72.447 & 309.5 & 72.45 & 0.162 \\
\hline $\mathrm{NF}_{3}$ & 150 & 123.0 & 234.0 & 0.174 & 44.607 & 234.0 & 44.61 & 0.126 \\
\hline $\mathrm{NH}_{3}$ & 187 & 210.2 & 405.4 & 0.180 & 113.390 & 405.4 & 113.33 & 0.256 \\
\hline $\mathrm{O}_{2}$ & 156 & 76.4 & 154.1 & 0.181 & 49.460 & 154.6 & 50.43 & 0.022 \\
\hline para Hydrogen & 183 & 15.5 & 32.9 & 0.173 & 12.838 & 32.9 & 12.84 & -0.218 \\
\hline Propene & 131 & 193.0 & 365.6 & 0.173 & 46.646 & 365.6 & 46.65 & 0.141 \\
\hline Propyne & 201 & 273.0 & 402.4 & 2.636 & 56.267 & 402.4 & 56.26 & 0.204 \\
\hline R11 & 141 & 255.2 & 471.1 & 0.175 & 44.076 & 471.1 & 44.08 & 0.189 \\
\hline R113 & 169 & 277.0 & 487.2 & 0.181 & 33.923 & 487.2 & 33.92 & 0.253 \\
\hline R114 & 201 & 273.2 & 418.8 & 0.882 & 32.516 & 418.8 & 32.57 & 0.252 \\
\hline R115 & 169 & 201.6 & 353.1 & 0.179 & 31.584 & 353.1 & 31.20 & 0.252 \\
\hline R116 & 201 & 173.1 & 293.0 & 0.261 & 30.477 & 293.0 & 30.48 & 0.257 \\
\hline R12 & 132 & 208.9 & 385.1 & 0.176 & 41.362 & 385.1 & 41.36 & 0.179 \\
\hline R123 & 136 & 260.5 & 456.8 & 0.177 & 36.619 & 456.8 & 36.62 & 0.282 \\
\hline R124 & 124 & 226.0 & 395.4 & 0.176 & 36.243 & 395.4 & 36.24 & 0.288 \\
\hline R125 & 174 & 195.0 & 339.2 & 0.176 & 36.179 & 339.2 & 36.18 & 0.305 \\
\hline R13 & 132 & 164.5 & 302.0 & 0.178 & 38.790 & 302.0 & 38.79 & 0.172 \\
\hline R134a & 157 & 214.8 & 374.2 & 0.177 & 40.591 & 374.2 & 40.59 & 0.327 \\
\hline R14 & 161 & 124.0 & 227.5 & 0.172 & 37.758 & 227.5 & 37.50 & 0.179 \\
\hline R141b & 140 & 263.6 & 477.5 & 0.178 & 42.117 & 477.5 & 42.12 & 0.220 \\
\hline R142b & 137 & 228.3 & 410.3 & 0.182 & 40.548 & 410.3 & 40.55 & 0.232 \\
\hline R143a & 165 & 194.6 & 345.9 & 0.173 & 37.618 & 345.9 & 37.61 & 0.262 \\
\hline R152a & 148 & 216.0 & 386.4 & 0.179 & 45.168 & 386.4 & 45.17 & 0.275 \\
\hline R21 & 165 & 244.0 & 451.5 & 0.177 & 51.842 & 451.5 & 51.81 & 0.206 \\
\hline R218 & 128 & 204.5 & 345.0 & 0.183 & 26.402 & 345.0 & 26.40 & 0.317 \\
\hline R22 & 134 & 200.7 & 369.3 & 0.174 & 49.900 & 369.3 & 49.90 & 0.221 \\
\hline R227ea & 135 & 222.1 & 376.0 & 0.171 & 29.991 & 376.0 & 29.99 & 0.354 \\
\hline R23 & 149 & 165.2 & 299.3 & 0.171 & 48.317 & 299.3 & 48.32 & 0.263 \\
\hline R236ea & 200 & 242.9 & 412.4 & 0.174 & 33.564 & 412.4 & 35.02 & 0.379 \\
\hline R236fa & 149 & 236.3 & 398.1 & 0.175 & 32.000 & 398.1 & 32.00 & 0.377 \\
\hline R245ca & 150 & 259.4 & 447.6 & 0.174 & 39.276 & 447.6 & 39.25 & 0.354 \\
\hline $\mathrm{R} 245 \mathrm{fa}$ & 155 & 251.1 & 427.2 & 0.176 & 36.366 & 427.2 & 36.40 & 0.372 \\
\hline
\end{tabular}




\begin{tabular}{lllllllll}
$\mathrm{R} 32$ & 149 & 192.2 & 351.3 & 0.175 & 57.826 & 351.3 & 57.82 & 0.277 \\
$\mathrm{R} 41$ & 201 & 175.0 & 317.3 & 0.290 & 58.970 & 317.3 & 58.97 & 0.201 \\
$\mathrm{RC318}$ & 201 & 233.4 & 388.4 & 0.195 & 27.780 & 388.4 & 27.77 & 0.355 \\
$\mathrm{SF}_{6}$ & 201 & 222.4 & 318.7 & 2.244 & 37.539 & 318.7 & 37.54 & 0.210 \\
$\mathrm{SO}_{2}$ & 173 & 230.3 & 430.6 & 0.182 & 78.753 & 430.6 & 78.84 & 0.256 \\
Toluene & 127 & 331.1 & 591.8 & 0.171 & 41.264 & 591.8 & 41.26 & 0.266 \\
Benzene & 182 & 305.6 & 562.1 & 0.177 & 49.012 & 562.1 & 48.94 & 0.209 \\
Water & 169 & 331.1 & 645.2 & 0.181 & 215.740 & 647.1 & 220.64 & 0.344 \\
$\mathrm{C}_{4} \mathrm{~F}_{10}$ & 155 & 234.4 & 386.3 & 0.174 & 23.290 & 386.3 & 23.23 & 0.374 \\
$\mathrm{C}_{5} \mathrm{~F}_{12}$ & 144 & 262.9 & 420.6 & 0.171 & 20.368 & 420.6 & 20.45 & 0.423 \\
\hline
\end{tabular}

The results showed the accuracy of designed ANN for estimating saturated vapor pressure. Table2 reports the average absolute relative deviation percent (AARD \%) of ANN compare to the commonly used models for 75 pure substances.

Table2: Average absolute relative deviation of the values obtained ANN model in comparison with other methods

\begin{tabular}{|c|c|c|c|c|c|c|c|}
\hline Substance & Lee-Kesler & Ambrose & Wagner & Antoine & Velasco & Riedel & ANN \\
\hline $\mathrm{C}_{1}$ & 0.17 & 0.03 & 0.14 & 1.85 & 0.47 & 0.66 & 0.08 \\
\hline $\mathrm{C}_{2}$ & 0.51 & 0.04 & 0.21 & 1.96 & 0.43 & 0.62 & 0.12 \\
\hline $\mathrm{C}_{3}$ & 0.75 & 0.05 & 0.25 & 1.55 & 0.49 & 0.54 & 0.11 \\
\hline $\mathrm{i}-\mathrm{C}_{4}$ & 0.54 & 0.17 & 0.02 & 1.08 & N.A. & 0.36 & 0.34 \\
\hline $\mathrm{n}-\mathrm{C}_{4}$ & 0.92 & 0.21 & 0.18 & 0.48 & 0.31 & 0.73 & 0.09 \\
\hline$n-C_{5}$ & 0.82 & 0.15 & 0.01 & 1.23 & 0.32 & 0.64 & 0.15 \\
\hline$n-C_{6}$ & 0.67 & 0.06 & 0.16 & 0.14 & 0.55 & 0.46 & 0.13 \\
\hline $\mathrm{C}_{7}$ & 3.17 & 0.09 & 0.04 & 0.19 & 0.43 & 0.39 & 0.12 \\
\hline $\mathrm{C}_{8}$ & 0.61 & 0.27 & 0.85 & 0.64 & 0.58 & 0.18 & 0.11 \\
\hline $\mathrm{C}_{9}$ & 0.46 & 0.16 & 0.28 & 0.22 & 0.46 & 0.44 & 0.12 \\
\hline $\mathrm{C}_{10}$ & 0.64 & 0.09 & 0.31 & 0.10 & 0.64 & 0.32 & 0.20 \\
\hline $\mathrm{C}_{12}$ & 0.63 & 0.10 & 0.37 & 0.08 & N.A. & 0.22 & 0.17 \\
\hline $\begin{array}{l}\text { 2,2-dimethy } \\
\text { propane }\end{array}$ & 0.05 & 0.29 & 0.07 & 0.12 & 0.43 & 0.14 & 0.04 \\
\hline $\begin{array}{l}\text { 2-methyl } \\
\text { pentane }\end{array}$ & 0.19 & 0.09 & 0.02 & 0.13 & 0.41 & 0.51 & 0.04 \\
\hline $\begin{array}{l}\text { 2-methyl } \\
\text { butane }\end{array}$ & 0.72 & 0.39 & 0.45 & 0.16 & 0.60 & 0.88 & 0.10 \\
\hline
\end{tabular}




\begin{tabular}{|c|c|c|c|c|c|c|c|}
\hline $\mathrm{CO}$ & 0.72 & 0.70 & 0.08 & 2.69 & 0.52 & 0.13 & 0.12 \\
\hline $\mathrm{CO}_{2}$ & 0.19 & 0.49 & 0.02 & 6.01 & N.A. & 14.47 & 0.12 \\
\hline $\cos$ & 0.22 & 0.36 & N.A. & 0.24 & 0.35 & 0.42 & 0.13 \\
\hline Cyc-Hexane & 0.51 & 0.55 & 0.18 & 0.06 & 0.34 & 0.13 & 0.04 \\
\hline Cyc-Propane & 0.20 & 0.10 & 0.16 & 1.48 & 0.91 & 0.92 & 0.29 \\
\hline $\mathrm{D}_{2} \mathrm{O}$ & 0.13 & 2.10 & N.A. & N.A. & N.A. & 2.52 & 0.15 \\
\hline Dutrium & 3.20 & 2.29 & N.A. & 14.47 & N.A. & 1.53 & 0.04 \\
\hline Ethene & 2.50 & 0.47 & 0.14 & 2.20 & 0.32 & 0.24 & 2.14 \\
\hline Flourine & 0.31 & 1.42 & 1.49 & 1.32 & 1.65 & 0.49 & 0.09 \\
\hline $\mathrm{H}_{2}$ & 0.71 & 0.45 & 0.03 & 1.61 & & 0.75 & 0.20 \\
\hline $\mathrm{H}_{2} \mathrm{~S}$ & 0.36 & 0.50 & N.A. & 2.52 & 0.32 & 0.35 & 0.22 \\
\hline $\mathrm{He}$ & 1.81 & 0.77 & 0.25 & 1.42 & N.A. & 1.58 & 0.08 \\
\hline $\mathrm{Ne}$ & 0.40 & 0.19 & 0.04 & 2.06 & 0.59 & 0.62 & 0.12 \\
\hline $\mathrm{Ar}$ & 1.07 & 0.25 & 0.01 & 0.43 & 0.47 & 0.27 & 0.12 \\
\hline $\mathrm{Kr}$ & 0.19 & 0.12 & 0.01 & 0.71 & 0.38 & 0.46 & 0.13 \\
\hline Xe & 0.14 & 0.20 & 0.01 & 0.28 & 0.45 & 0.35 & 0.08 \\
\hline $\mathrm{N}_{2}$ & 1.04 & 0.60 & 0.23 & 4.48 & N.A. & 2.12 & 0.55 \\
\hline $\mathrm{N}_{2} \mathrm{O}$ & 0.14 & 0.34 & 0.07 & 2.02 & N.A. & 0.11 & 0.12 \\
\hline $\mathrm{NF}_{3}$ & 0.65 & 0.22 & N.A. & 0.41 & 0.49 & 0.42 & 0.07 \\
\hline $\mathrm{NH}_{3}$ & 1.86 & 0.88 & 0.02 & 0.69 & 0.82 & 1.42 & 0.18 \\
\hline $\mathrm{O}_{2}$ & 0.42 & 0.29 & 0.02 & 1.53 & 0.37 & 0.43 & 0.80 \\
\hline \multicolumn{8}{|l|}{ para } \\
\hline Hydrogen & 0.20 & 0.64 & N.A. & N.A. & N.A. & 0.84 & 0.20 \\
\hline Propene & 0.48 & 0.28 & 0.21 & 0.15 & 0.32 & 0.36 & 0.08 \\
\hline Propyne & 0.91 & 0.65 & 0.69 & 8.45 & 0.82 & 2.50 & 0.19 \\
\hline R11 & 0.53 & 0.23 & 0.36 & 0.44 & 0.39 & 0.36 & 0.05 \\
\hline R113 & 0.42 & 0.24 & 0.27 & 1.02 & 0.32 & 0.25 & 0.18 \\
\hline R114 & 0.24 & 0.10 & 0.29 & 0.24 & 0.32 & 0.27 & 0.12 \\
\hline R115 & 0.73 & 0.29 & 0.54 & 0.50 & 1.43 & 0.56 & 0.06 \\
\hline R116 & 0.54 & 0.06 & 0.74 & 1.18 & 0.40 & 0.40 & 0.12 \\
\hline R12 & 0.68 & 0.09 & 0.22 & 1.66 & N.A. & 0.52 & 0.11 \\
\hline R123 & 0.49 & 0.21 & 0.11 & N.A. & 0.30 & 0.28 & 0.16 \\
\hline R124 & 0.46 & 0.23 & 0.11 & 0.95 & 0.34 & 0.25 & 0.14 \\
\hline R125 & 0.45 & 0.23 & 0.51 & 4.21 & 0.52 & 0.25 & 0.14 \\
\hline R13 & 0.46 & 0.27 & 0.35 & 6.45 & 0.35 & 0.34 & 0.14 \\
\hline
\end{tabular}




\begin{tabular}{|c|c|c|c|c|c|c|c|}
\hline R134a & 0.71 & 0.06 & 0.03 & 9.73 & N.A. & 0.46 & 0.14 \\
\hline R14 & 0.72 & 0.10 & 1.36 & 1.51 & 0.94 & 0.55 & 0.16 \\
\hline R141b & 0.33 & 0.42 & 0.41 & N.A. & N.A. & 0.14 & 0.14 \\
\hline R142b & 0.66 & 0.14 & 0.16 & 3.52 & N.A. & 0.47 & 0.16 \\
\hline R143a & 1.14 & 0.44 & 0.06 & 1.91 & N.A. & 0.91 & 0.15 \\
\hline R152a & 1.24 & 0.49 & 0.03 & 4.56 & N.A. & 0.98 & 0.14 \\
\hline R21 & 0.13 & 0.66 & 0.79 & 1.81 & 0.62 & 0.06 & 0.18 \\
\hline R218 & 0.56 & 0.15 & 0.75 & 3.06 & N.A. & 0.36 & 0.22 \\
\hline R22 & 0.63 & 0.16 & 0.57 & 0.26 & 0.46 & 0.42 & 0.12 \\
\hline R227ea & 0.59 & 0.08 & 0.55 & N.A. & N.A. & 0.35 & 0.22 \\
\hline R23 & 1.22 & 0.44 & 0.12 & 1.45 & 0.36 & 0.94 & 0.12 \\
\hline R236ea & 1.85 & 1.18 & 2.49 & 23.81 & N.A. & 1.58 & 0.21 \\
\hline R236fa & 0.42 & 0.23 & 0.47 & 4.51 & N.A. & 0.17 & 0.13 \\
\hline R245ca & 0.79 & 0.18 & 0.02 & 4.89 & N.A. & 0.48 & 0.12 \\
\hline R245fa & 0.15 & 0.57 & 0.04 & 85.82 & N.A. & 0.17 & 0.15 \\
\hline R32 & 1.81 & 1.00 & 0.29 & 1.21 & 0.36 & 1.47 & 0.14 \\
\hline R41 & 1.55 & 0.86 & 0.63 & 1.26 & 0.50 & 1.44 & 0.28 \\
\hline RC318 & 0.13 & 0.51 & 0.05 & 1.22 & N.A. & 0.14 & 0.13 \\
\hline $\mathrm{SF}_{6}$ & 0.52 & 0.24 & N.A. & 20.86 & N.A. & 1.28 & 0.12 \\
\hline $\mathrm{SO}_{2}$ & 0.66 & 0.26 & N.A. & 0.75 & 0.44 & 0.38 & 0.43 \\
\hline Toluene & 1.10 & 0.37 & 0.26 & 1.19 & 0.42 & 0.85 & 0.17 \\
\hline Benzene & 0.15 & 0.61 & 0.18 & 1.35 & 0.31 & 0.14 & 0.13 \\
\hline Water & 3.73 & 2.62 & N.A. & 1.78 & 0.73 & 3.04 & 2.07 \\
\hline $\mathrm{C}_{4} \mathrm{~F}_{10}$ & 0.68 & 0.65 & 0.21 & 1.53 & 0.48 & 0.21 & 0.21 \\
\hline $\mathrm{C}_{5} \mathrm{~F}_{12}$ & 0.47 & 2.96 & 1.39 & N.A. & 0.53 & 0.59 & 0.16 \\
\hline
\end{tabular}

Where "N.A." means the parameters of model is not available for considered substance.

Table3 presents the statistical parameters including average absolute percentage relative deviation percentage (AARD\%), average relative deviation, (ARD\%), and mean square error (MSE) of the considered models and the ANN model. 
Table3. Statistical parameter of ANN and considered models

\begin{tabular}{lccc}
\hline & AARD\% & ARD\% & MSE \\
\hline Antoine & 4.003 & -1.354 & 7.485 \\
Ambros-Walton & 0.485 & 0.022 & 1.154 \\
Riedel & 0.902 & 0.067 & 2.471 \\
Wagner & 0.332 & -0.123 & 0.896 \\
Lee-Kesler & 0.755 & -0.161 & 1.596 \\
Velasco et al. & 0.513 & 0.454 & 0.934 \\
This Study & 0.211 & -0.007 & 0.422 \\
\hline
\end{tabular}

The preciseness of ANN system for correlating the experimental data of saturated vapor pressure for all 75 substances was shown in Figure 5

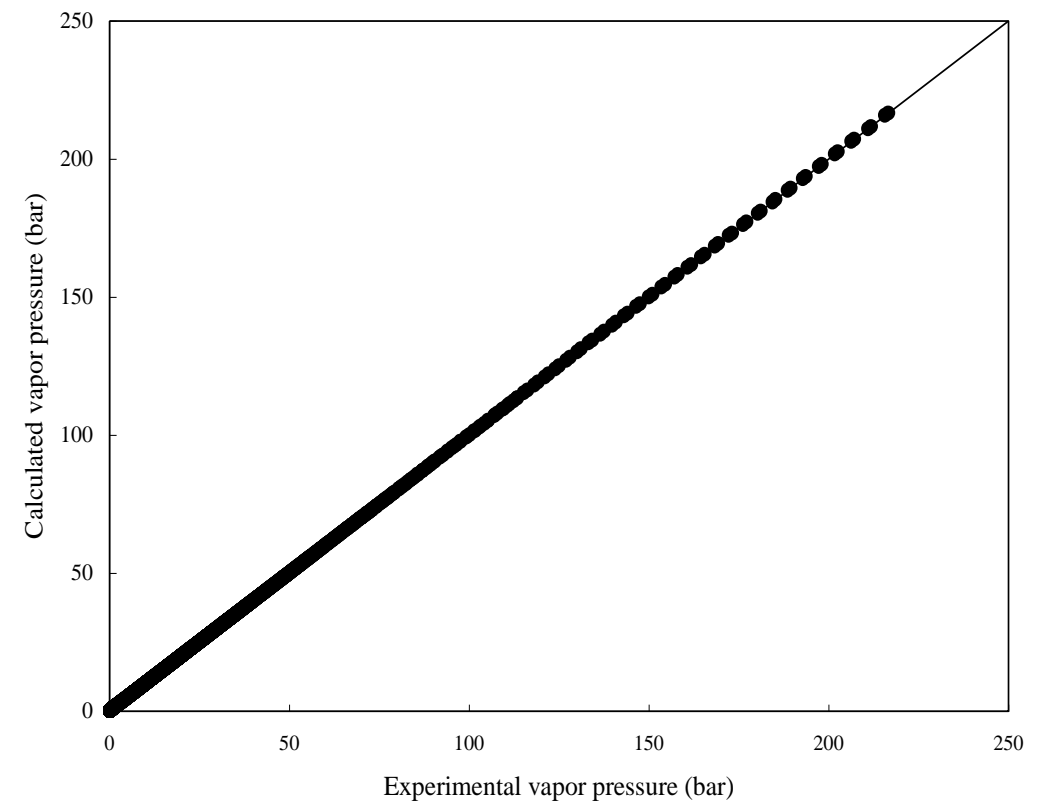

Figure5: Experimental versus predicted saturation vapor pressure for all data

To more consideration of the designed ANN, Figure6 shows the cumulative frequency of obtained network versus AARD\% of ANN compared to all other models. It shows the accuracy of presented 
method in estimation of saturated vapor pressure for more than 12000 data points as compared to other six methods discussed in this study.

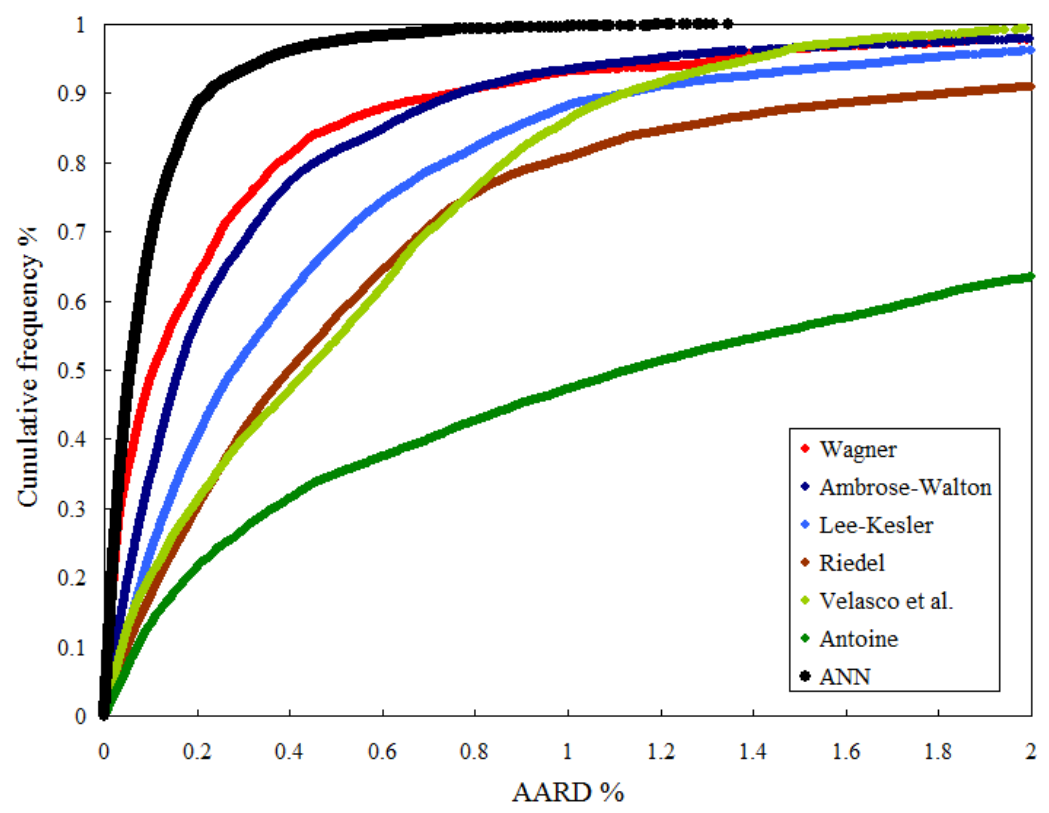

Figure6: AARD\% of various methods in calculating vapor pressure as function of cumulative frequency

The new method has successfully predicted $89 \%$ of the all measurements with AARD\% of less than 0.2 and $98 \%$ of the data with AARD\% of less than $0.5 \%$. Wagner, which is the second accurate method, predicted $64 \%$ of the vapor pressure measurements with AARD\% of less than 0.2 , and $85 \%$ of the data with AARD\% of less than $0.5 \%$. Hence the neural network advantage over all the methods was considered in this study.

As reported in results, the designed ANN is much more accurate than other methods for prediction of saturated vapor pressure.

\section{Conclusion}

An accurate ANN model to predict vapor pressures of pure compounds from knowledge of the temperature, critical temperature, critical pressure, and acentric factor is presented. Also various vapor pressure prediction methods are compared and evaluated. A new artificial neural network (ANN) based on LMA algorithm back-propagation method was recommended to estimate vapor pressure of pure substances more accurate than other commonly used models. To validate the proposed method, the vapor pressures of 75 pure substances with 12000 data points have been examined and an overall average absolute percentage deviation of $0.211 \%$ is achieved.

\section{Acknowledgements}

The supports of Tiran branch of Islamic Azad University for supporting this work are gratefully acknowledged. 


\section{References}

[1] J. V. Sengers, R. F. Kayser, C. J. Peters, and H. J. White, Equations of state for fluids and fluids mixtures, , Elsevier, Amsterdam, The Netherlands, 2000.

[2] O. Redlich, and J. N. S. Kwong, Chemical Reviews. 44 (1949) 233-244.

[3] G. Soave, Chemical Engineering Science. 72 (1972) 1197-1203.

[4] D. Y. Peng, and D. B. Robinson, Ind. Eng. Chem. Fund. 15 (1976) 59-64.

[5] S. Velasco, F. L. Roma'n, J. A. White, and A. Mulero, J. Chem. Thermodynamics. 40 (2008) 789797.

[6] E. Sanjari, M. Honarmand, H. Badihi, A. Ghaheri, Int. J. Refrigeration. 36 (2013) 1327-1332.

[7] E. Sanjari, M. Honarmand, N. Afshar, R.S. Esfahani, Thermochimica Acta. 556 (2013) 30-33.

[8] K. Mejbri, and A. Bellagi, Thermochimica Acta. 436 (2005) 140-149.

[9] J. Lielmezs, K. G. Astley, and J. A. McEvoy, Thermochimica Acta. 52 (1982) 9-18.

[10] F. L. Figueira, L. Lugo, and C. Olivera-Fuentes, Fluid Phase Equilibria. 259 (2007) 105-115.

[11] L. A. Forero, and J. A. Velásquez, J. Chem. Eng. Data. 55 (2010) 5094-5100.

[12] M. Aznar, A. Silva-Telles, and J. O. Valderrama, Chem. Eng. Comm. 190 (2003) 1411-1426.

[13] E. Voutsas, M. Lampadariou, K. Magoulas, and D. Tassios, Fluid Phase Equilibria. 198 (2002) 8193

[14] W. Wagner, Cryogenics. 13 (1973) 470-482.

[15] C. Antoine, Comptes Rendus. 107 (1888) 681-836.

[16] R. C. Reid, J. M. Prausnitz, and B. E. Poling, The Properties of Gases and Liquids, 4th ed., McGrawHill, 1987

[17] B. E. Poling, J. M. Prausnitz, and J. P. O'Connell, The Properties of Gases and Liquids, 5th ed., McGraw-Hill, 2001.

[18] E. W. Lemmon, and A. R. Goodwin, J. Phys. Chem. Ref. Data. 29 (2000) 1-39

[19] S. N. Sivanandam, S. Sumathi, and S. N. Deepa, Introduction to Neural Networks Using Matlab 6.0. McGraw-Hill Publishing, New Delhi, 2006.

[20] A. R. Moghadasi, F. Parvizian, S. M. Hosseini, and A. R. Fazlali, Braz. J. Chem. Eng. 26 (2009) 199206.

[21] A. A. Rohani, G. Pazuki, H. A. Najafabadi, S. Seyfi, and M. Vossoughi, Exp. Sys. Appl. 38 (2011) 1738-1747.

[22] J. A. Lazzús, Thermochimica Acta. 489 (2009) 53-62.

[23] P. Gandhidasan, and M. A. Mohandes, Appl. Therm. Eng. 28 (2008) 126-135.

[24] NIST Chemistry WebBook, NIST Standard Reference Database Number 69, National Institute of Standards and Technology, Gaithersburg MD, p. 20899, http://webbook.nist.gov.

[25] B. I. Lee, and M. G. Kesler, AlChE Journal. 21 (1975) 510-527. 
[26] M. Gude, and A. S. Teja, J. Chem. Eng. Data. 40 (1995) 1025-1036.

[27] C. Tsonopoulos, and D. Ambrose, J. Chem. Eng. Data. 40 (1995) 547-558.

[28] K. N. Marsh, A. Abramson, D. Ambrose, D.W. Morton, E. Nikitin, C. Tsonopoulos, and C. L. Young, J. Chem. Eng. Data. 52 (2007) 1509-1538.

[29] L. Riedel, Chem. Ing. Tech. 26 (1954) 679-683.

[30] L. A. Forero, and J. A. Velásquez, J. Chem. Thermodynamics. 43 (2011) 1235-1251.

[31] A. Sencan, and S. A. Kalogirou, Energy. Conv. Man. 46 (2005) 2405-2418.

[32] E. Sanjari, and E. Nemati Lay, J. Nat. Gas. Sci. Eng. 9 (2012) 220-226.

[33] R. Eslamloueyan, and M. H. Khademi, Int. J. Therm. Sci. 48 (2009) 1094-1101.

[34] H. Esen, and M. Inalli, Exp. Sys. Appl. 36 (2009) 10229-10238.

[35] E. Nemati Lay, M. Peymani, and E. Sanjari, World Academy of Science, Engineering and Technology. 67 (2012) 340-346. 